\title{
Rekomendasi Langkah Nyata Pastikan Bisnis Anda Berhasil
}

\section{Sifaun Nadiro}

\author{
Universitas Nahdlatul Ulama Sidoarjo \\ sifaun@tutanota.com
}

Memulai bisnis impian Anda adalah impian yang menjadi kenyataan bagi banyak orang yang selalu ingin memilikinya. Ini bisa sangat mendebarkan sekaligus bermanfaat, tetapi ada banyak jebakan dan tantangan dalam prosesnya. Jadi, jika Anda telah membuat keputusan untuk memulai bisnis Anda atau lebih tepatnya Anda bosan bekerja di bawah seseorang, selamat datang. Tetapi, bersiaplah untuk meluangkan beberapa jam lagi untuk mencapai tujuan jangka panjang Anda.

Menurut sebuah studi yang diterbitkan oleh Small Business Administration (SBA) USA pada startup, sekitar 50 persen startup gagal di tahun pertama bisnis mereka dan 95 persen gagal dalam lima tahun pertama. Kebanyakan pemilik bisnis baru akan selalu bertanya pada diri mereka sendiri, "Apa yang harus kami lakukan sekarang?", Itu setelah mendirikan bisnis baru mereka. Setelah bekerja untuk seseorang selama beberapa tahun, Anda yakin 
Anda memiliki keterampilan yang cukup dan dorongan untuk membuatnya di dunia wirausaha. Nah, keputusan untuk menjelajah ke dunia wirausaha yang menggiurkan ini hanyalah langkah pertama. Berikut beberapa langkah agar Anda sukses dan memastikan bisnis Anda berhasil.

\section{Minta Bantuan}

Tidak ada yang mencapai apapun sendirian. Tentu, Anda mungkin berpikir Anda pernah melakukannya pada satu titik dalam hidup Anda, tetapi Anda tidak melakukannya; Saya yakinkan Anda seseorang (mungkin banyak orang) membantu Anda di sepanjang jalan.Ingatlah hal ini dan jangan takut untuk meminta bantuan ketika Anda mencoba membuat ulang diri Anda sendiri. Anda tidak perlu pergi sejauh untuk memiliki seorang mentor, tetapi Anda harus rela mencari (Zarpentine, 2016).

\section{Pemasaran dengan Anggaran yang Ketat}

Memasarkan bisnis baru Anda sangat penting tetapi tidak harus membebani bumi. Media sosial adalah teman Anda - membuat halaman bisnis Anda di Facebook gratis dan akan membantu peringkat pencarian online Anda. Jadi mengirimkan URL situs web Anda ke mesin pencari seperti Google dan Bing - sepenuhnya gratis. Juga perhatikan grup Facebook komunitas - beberapa 
akan memerlukan biaya iklan yang kecil sementara yang lain memungkinkan Anda untuk mengiklankan bisnis Anda pada hari-hari tertentu dalam seminggu. Intinya dengan pemasaran adalah mencoba apa saja. Anda tidak akan tahu apa yang akan bekerja untuk Anda sampai Anda mencobanya (Santam, 2018).

\section{Percayai Diri Anda}

Bijaksana dan pantang menyerah dalam belajar dan berwirausaha adalah kunci kesuksesan hidup dan wirausaha (Nahdiyah, Amrina, Purnomo, \& Rosyidah, 2017). Ini penting, karena kepercayaan pada diri sendiri dapat membuat semua perbedaan di dunia. Bahkan jika Anda pernah mengalami kegagalan di masa lalu, selalu percaya bahwa Anda akan berhasil pada apa pun yang Anda rencanakan untuk capai. Jika Anda akan membuat ulang diri sendiri dan menemukan keberhasilan melakukannya, Anda harus percaya bahwa setiap keputusan yang Anda buat akan menjadi keputusan yang tepat. Jika Anda mulai menebak-nebak diri sendiri, Anda akan berakhir tersesat tanpa tahu ke mana Anda pergi. Anda tidak akan pernah membuat orang lain percaya pada Anda kecuali jika Anda percaya pada diri sendiri terlebih dahulu, jadi sebagai wirausahawan, selalu pastikan kepercayaan diri Anda tinggi dan Anda percaya bahwa Anda akan berhasil (Zarpentine, 2016). 


\section{Jangan Mencoba Membuat Produk yang Sempurna dengan Cara yang Benar dan Mulailah dan Mulai Penjualan}

Dunia dan masyarakat membutuhkan kewirausahaan (Setyawati, Purnomo, Irawan, Tamyiz, \& Sutiksno, 2018). Uang mengikuti momentum, bukan kesempurnaan. Itu berarti bahwa Anda tidak benar-benar membutuhkan situs web Anda sempurna dan kursus Anda juga tidak perlu sempurna. Mulailah dan dapatkan penjualan, itu bagian terpenting di awal (Basu, 2018).

\section{Teliti Persaingan}

Edupreneur atau educational entrepreneur berasal dari dua kata yaitu education bermakna pendidikan dan entrepreneur bermakna pengusaha atau wirausahawan. Ada juga yang menyamakan istilah edupreneur dengan istilah teacherpreneur (Purnomo, 2017). Pengusaha yang sukses selalu menjaga mata dan telinganya terbuka ketika angin membawa informasi yang kuat untuk dimanfaatkan. Terus ikuti perkembangan riset produk atau layanan kompetitif di pasar, bersama-sama mengawasi perkembangan baru dan peningkatan dari pesaing Anda. Ini akan menjaga tanggung jawab untuk memberikan penawaran unik, terus-menerus, dan membantu Anda mendorong diri Anda untuk 
menciptakan solusi baru untuk masalah kuno (Chakraborty, 2017).

\section{Cari Cara untuk Melayani Audiens dan Pelanggan Anda dengan Lebih Baik}

Lihatlah audiens yang kamu sukai. Lebih baik lagi, perhatikan baik-baik mereka yang sudah membeli dari Anda. Jika Anda sudah memiliki daftar 5.000 atau lebih, alih-alih berfokus pada menambahkan ke daftar email Anda atau menumbuhkan audiens media sosial Anda, fokuslah untuk membuat konten baru untuk orang-orang yang sudah Anda sukai. Produk atau program baru apa yang mereka butuhkan selanjutnya? Buat untuk mereka dan Anda akan membangun rangkaian produk. Kami memiliki rangkaian produk dari 3 program inti dan setiap program dibangun menjadi program berikutnya. Itu memungkinkan kami untuk terus mendukung audiens yang telah kami tarik sambil juga meningkatkan pendapatan kami (Basu, 2018).

\section{Kurang Bekerja}

Pengusaha pemula tidak menghitung jam kerja mereka. Mereka bekerja tanpa henti dan terkadang terlalu banyak! Hanya sedikit orang yang akan memberi tahu Anda untuk bekerja lebih sedikit. Tapi saya tidak malu atau malu untuk 
mengatakannya. Sangat penting untuk menemukan keseimbangan antara proyek Anda dan kehidupan pribadi. Jika Anda tidak membiarkan diri Anda cukup mengisi dalam berbagai aspek kehidupan Anda, proyek Anda akan berakhir dengan mengambil alih sepenuhnya dan Anda tidak akan lagi efektif. Penting untuk mengambil langkah mundur dan mencari tahu di mana Anda berada. Anda harus melakukan penyesuaian sesuai kebutuhan. Jika proyek ini menghabiskan terlalu banyak ruang dalam hidup Anda, Anda secara tidak langsung akan merusak keberhasilannya (L'Écuyer, 2016).

\section{Melaksanakan Perintah Langit}

Tips mengelola institusi pendidikan wirausaha adalah niat mendidik dan berjuang karena Allah ta'ala. Niscaya rintangan sebesar apapun akan terasa ringan dihadapan kita (Yuniarti, Kautsari, Sholichah, Purnomo, \& Rosyidah, 2017). Setiap manusia yang memiliki ilmu termasuk ilmu wirausaha selayaknya harus mengamalkan ilmu tersebut (Asitah, Usmawati, Rosyidah, \& Purnomo, 2017). Pemimpin wirausaha harus seperti Ilmu Nahwu dalam Bahasa Arab yaitu harus bisa Marfu' (dhummah) dan Manshub (fathah), jangan seperti Majrur dan Majzum. Marfu' yang berarti memeluk atau merangkul, sedangkan Manshub yang berarti 
terbuka tanpa ada yang ditutupi. Jangan seperti Majrur yang berarti menginjak-injak atau merendahkan orang lain. Seperti kata orang dahulu, yaitu Ngeluruk Tanpo Bolo, Menang Tanpo Ngasorake, Sakti Tanpo Aji-Aji, Sugeh Tanpo Bolo (Maula, Mufidah, Rosyidah, \& Purnomo, 2017; Qori'ah, Sholichah, Purnomo, \& Rosyidah, 2017). Wirausaha senantiasa harus selalu berpegang teguh pada sifat yang dimiliki oleh Rasul agar sesuatu yang di kerjakan mendapat kepercayaan dari orang lain (Munjidah, Zannah, Purnomo, \& Rosyidah, 2017).

\section{Bersiap untuk Tantangan Keuangan}

Arus kas merupakan tantangan terbesar mereka. Menangani pukulan aliran uang dengan menabung untuk pengeluaran selama sebulan atau dengan menjadi kreatif dengan cara Anda menurunkan biaya overhead. Anda dapat menawarkan diskon kepada klien jika mereka membayar setoran atau jumlah penuh dimuka, atau bahkan insentif - mis. bayar $10 \%$ lebih sedikit jika Anda mengirim produk atau layanan Anda seminggu sebelumnya. Apa pun yang Anda lakukan, berhati-hatilah terhadap hutang - ini adalah salah satu pembunuh terbesar kesuksesan bisnis kecil (Santam, 2018). Pendidikan wirausaha bertujuan menyampaikan ilmu dan mentransformasi orang 
lain menjadi pengusaha yang lebih baik (Fidiana, Istiana, Rosyidah, \& Purnomo, 2017). Senantiasa belajar dan bekerja keras. Bersabarlah dengan masalah, sesungguhnya didalam kesulitan ada kemudahan (Sholichah, Istiqomah, Rosyidah, \& Purnomo, 2017).

\section{Pelajari Cara Mempromosikan Diri Sendiri}

Elevator Pitch yang baik dan kepercayaan diri dapat membawa Anda naik level. Upaya pemasaran pertama perusahaan mana pun datang langsung dari pendirinya. Pastikan Anda menghabiskan waktu mempelajari cara-cara terbaik untuk membagikan visi Anda tanpa terdengar seperti Anda memberikan promosi penjualan. Ingatlah bahwa Anda selalu perlu fokus pada klien (Reynolds, 2016).

\section{Jangan Hanya Fokus untuk Mendapatkan Penjualan dan Fokus untuk Membantu Pelanggan Anda Berhasil}

Pengusaha tidak berada dalam bisnis ini untuk hanya membuat orang membeli barangbarang pengusaha. Pengusaha ingin mereka melihat perubahan dan dampaknya serta menciptakan kisah sukses (Basu, 2018). 


\section{References}

Asitah, N., Usmawati, D. Z., Rosyidah, E., \& Purnomo, A. (2017). MI Hasyim Asy'ari Ilmu Harus Terus Mengarus. In Wirausaha Pendidikan Indonesia (Jilid 2). Sidoarjo: UNUSIDA Press.

Basu, T. (2018). Top 20 Tips for Building a Business from Successful Entrepreneurs. Retrieved May 19, 2019, from https://www.thinkific.com/blog/tipsbuilding-a-business-successful-entrepreneurs/ Chakraborty, R. (2017). \#7 Best Tips for First-time Entrepreneurs. Retrieved June 4, 2019, from https://www.entrepreneur.com/article/298901

Fidiana, W., Istiana, Z., Rosyidah, E., \& Purnomo, A. (2017). MINU Waru 2 Insan Berkilau Cahaya Manfaat. In Wirausaha Pendidikan Indonesia (Jilid 4). Sidoarjo: UNUSIDA Press.

L'Écuyer, J.-P. (2016). Ten Tips to Becoming a Better Entrepreneur. Retrieved May 20, 2019, from https://www.futurpreneur.ca/en/2016/ten-tips-tobecoming-a-better-entrepreneur/

Maula, I., Mufidah, F. I., Rosyidah, E., \& Purnomo, A. (2017). SD Antawirya Islamic Javanese School Mother is Culture. In Wirausaha Pendidikan Indonesia (Jilid 1). Sidoarjo: UNUSIDA Press.

Munjidah, A., Zannah, I. P. N., Purnomo, A., \& Rosyidah, E. (2017). MI Thoriqussalam Berpegang Kepada Rosul. In Wirausaha Pendidikan Indonesia (Jilid 4). Sidoarjo: UNUSIDA Press.

Nahdiyah, K., Amrina, S., Purnomo, A., \& Rosyidah, E. (2017). SD Taman Pendidikan Islam Porong Iman Kuat Bekal di Akhirat. In Wirausaha Pendidikan Indonesia (Jilid 2). Sidoarjo: UNUSIDA Press. 
Purnomo, A. (2017). Pengertian Edupreneur. https://doi.org/10.31227/osf.io/8fnu6

Qori'ah, S., Sholichah, S. A., Purnomo, A., \& Rosyidah, E. (2017). Progresif Bumi Sholawat dengan Kebenaran Semua Pasti Ada Jalan. In Wirausaha Pendidikan Indonesia (Jilid 3). Sidoarjo: UNUSIDA Press.

Reynolds, C. (2016). 8 Tips For Becoming a Successful Entrepreneur. Retrieved June 4, 2019, from https://www.business2community.com/strategy/8tips-becoming-successful-entrepreneur-01567069

Santam. (2018). 10 tips for becoming a successful entrepreneur. Retrieved June 11, 2019, from https://www.santam.co.za/blog/businessadvice/10-tips-for-becoming-a-successfulentrepreneur/

Setyawati, I., Purnomo, A., Irawan, D. E., Tamyiz, M., \& Sutiksno, D. U. (2018). A Visual Trend of Literature on Ecopreneurship Research Overviewed within The Last two Decades. Journal of Entrepreneurship Education, 21(4), 1-7. Retrieved from https://www.abacademies.org/articles/a-visualtrend-of-literature-on-ecopreneurship-researchoverviewed-within-the-last-two-decades7468.html

Sholichah, S. A., Istiqomah, A., Rosyidah, E., \& Purnomo, A. (2017). MI Darun Najah Berfikir Berkarya Berdzikir. In Wirausaha Pendidikan Indonesia (Jilid 3). Sidoarjo: UNUSIDA Press.

Yuniarti, D., Kautsari, M. F., Sholichah, F., Purnomo, A., \& Rosyidah, E. (2017). SMP SMA Al-Amin Ponpes Bahrul Hidayah Serahkan pada Allah Ta'ala. In Wirausaha Pendidikan Indonesia (Jilid 1). Sidoarjo: UNUSIDA Press. 
Zarpentine, B. (2016). 10 Great Tips on How to

Reinvent Yourself as an Entrepreneur. Retrieved June 9, 2019, from https://blog.cake.hr/how-toreinvent-yourself-as-an-entrepreneur/ 